\title{
Risk Factors for Acute Otitis Mediain Children at Dr.Soedono Hospital
}

\author{
Jeem Yaltafit Abror*, Andriani RussyNovita*, Suwondo Slamet ** \\ DOI: http://dx.doi.org/10.19106/JMedScieSup0050012018013
}

\begin{abstract}
Acute otitis media (OMA) was the most common ear infection in children. Because of tuba eustachius is not developed yet, shorter and flatter/horizontal in children sothe secretions of nasopharynx are easier to enter the middle ear. OMA can cause many complications such as subperiosteal abscess to severe complications like meningitis and brain abscess. Epidemiological studies of OMA in developing countries are still rare. The prevalence of OMA is different in many countries, ranging from 2.3-20\%. The result of study showed that the prevalence of OMA in children in East Jakarta was 5.38\%, and the highest prevalence was on group among 2-5 years old. Total of 179 patients analyzed were $50.8 \%$ male and $49.2 \%$ female. The mean age of this study subjects was 4.75 years (SD4.54). Of the $31.3 \%$ were diagnosed with OMA. There was no difference in the location of the OMA occurrence between the right and left ear. There was a significant correlation between age factor and the incidence of OMA $(p=0.014)$ and subjects which under 5 years of old became a risk factor for OMA. The results also showed that there was a correlation between treatment and the incidence of OMA $(p=0.000), A R I$ patients without treatment was being a risk factor for the incidence of OMA in children. There was no correlation between sex, type factor, and health insurance against the occurrence of OMA.
\end{abstract}

Keywords: acute otitis media - children - risk factor 